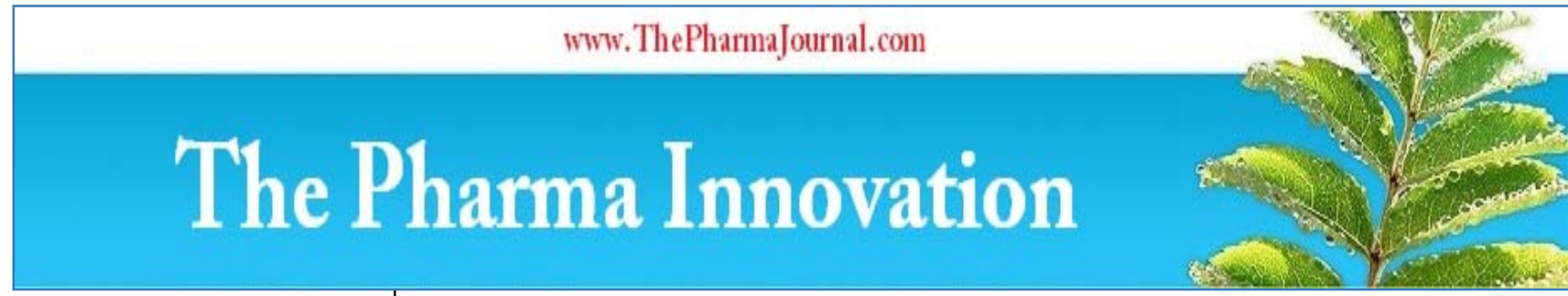

ISSN (E): 2277 - 7695

ISSN (P): 2349-8242

NAAS Rating: $\mathbf{5 . 0 3}$

TPI 2020; 9(6): 392-396

(C) 2020 TPI

www.thepharmajournal.com

Received: 15-04-2020

Accepted: 17-05-2020

\section{Ananya Panwar}

Department of Food Technology,

School of Applied and Life

Sciences, Uttaranchal

University, Dehradun, India

Yashodhara Singh

Department of Food Technology,

School of Applied and Life

Sciences, Uttaranchal

University, Dehradun, India

Bindu Naik

Department of Food Technology, School of Applied and Life

Sciences, Uttaranchal

University, Dehradun, India
Corresponding Author: Ananya Panwar

Department of Food Technology,

School of Applied and Life

Sciences, Uttaranchal

University, Dehradun, India

\section{Nutritional and pharmacological health benefits of Bombax ceiba L.}

\author{
Ananya Panwar, Yashodhara Singh and Bindu Naik
}

DOI: https://doi.org/10.22271/tpi.2020.v9.i6f.4799

\section{Abstract}

Bombax ceiba L. also called red silk cotton tree is a large deciduous tree which belongs to family Bombacaceae. The tree and its many parts such as leaves, bud, flower, stem bark, roots and gum are claimed for its therapeutic and used in pharmacologic activities like Cytotoxicity, Anti-inflammatory, Anti-diabetic, Hypotensive, Anti-obesity, Antioxidant, Antiangiogenic, Antimicrobial, and Aphrodisiac. It is noted to contain some important phyto constituents like mangiferin, vanillin, anthocyanins, polysaccharides, shamimin and lupeol. This paper is an overview to support the credibility of B. ceiba with the few scientific studies that have been conducted so far.

Keywords: Bombax ceiba, Phyto constituents, Pharmacological activities, Nutritional properties, Antioxidant activity.

\section{Introduction}

Bombax ceiba belonging to family Bombacaceae also known as silk cotton tree and commonly called semal. Bombax ceiba found in Northern Australia, India, Sri Lanka, Pakistan, Bangladesh, Myanmar, Malaysia, Java and Sumatra (Rameshwar et al., 2014) ${ }^{[18]}$. Bombax ceiba has many significant medicinal values. The tree is a powerful, fast-growing lightdemander. It thrives especially in valleys, on sandy loams that are deep and in regions with annual rainfall of 50 to $460 \mathrm{~cm}$ (Chaudhary and Khadabadi, 2012) ${ }^{[5]}$. Bombax ceiba found in India is a tall deciduous tree with characteristic woody thorns on the bark of the tree (Griffiths et al., 2003) ${ }^{[9]}$. This tree produces huge, crimson, ornithophilous flowers. The flowers have a firm perianth with rigid filaments and well protected ovaries (Saklani et al., 2013) ${ }^{[19]}$. Nearly all parts of Bombax ceiba, are known to have different medicinal properties which is proved by ethno botanists in many surveys and in the traditional medicine system such as Ayurvedic. Bark has hard-sharp conicles and grey-brown or silver-grey colored. The leaves are broad, spreading, glabrous, lanceolate with having 3-7 leaflets. The seeds of plant are shiny, black or brown, embodied in wool viz long and white, irregularly shaped obovoid, oily and shiny with thick, silky hair. Gum of tree is light brown to translucent locally known as "KATIRA"(Karole et al., 2017) ${ }^{[13]}$.

In Bombax ceiba presence of xanthones, flavonoids, quinines, triterpenes, sterols, hydrocarbons, fatty acids and their esters is distinguished phytochemically and for its various pharmacological activities such as, cytotoxicicity, anti oxidant, hypotensive, antiangiogenic, anti-inflammatory, anti-diabetic, and anti-microbial (Mostafa, 2018) ${ }^{[15]}$.

\section{Phytoconstituents}

Phytoconstituents are anything but chemical components which occur naturally in plants and which are accountable for the various organoleptic and therapeutic characteristics of plants (Mehta et al., 2018) ${ }^{[14]}$. Ceiba comprises of many important phytoconstituents substances, like proteins, alkaloids, glycosides, phytosterols and phenolic components like Quercetin, shamimin, mangiferin, kaemferol and derivatives of naphthalene (Gadge and Jalalpure, 2012) ${ }^{[6]}$. Roots of the tree were found to possess chemical components like bombaxquinone B, 2- o methyl isohemigossylic acid lactone, 9- cardinane sesqui terpenoids which were 4 existing and 5 novel components also HGC and lacinilene $\mathrm{C}$ were found to be present. Detailed analysis of phytochemical properties together with TLC ratios of various B extracts. Presence of alkaloids and coumains is reported in Bombax tree along with flavonoids, amino acids in alcoholic as 
well as aqueous extracts (Chaudhary and Khadabadi, 2012) [5]. Phytochemical analysis of the gynaecium section of the flower using chromatographic techniques from ethanolic extract of ethyl acetate fraction led to the separation of quercetagein glycoside. By spectroscopic methods, structure of the isolated compound has been explained including $1 \mathrm{H}$, UV and 13CNMR. Shamirnin, a recently discovered Cglycoside, flavones was isolated in form of yellow powder from the ethanolic extract of young leaves of the plant. The $\mathrm{Ph} . \mathrm{D}$. research proposed by Muhammad Ali Versiani examined the phytochemical studies of B. Ceiba. The plant extracts of dried leaf were led to a chemical investigation which led to the discovery of three new compounds 2-C- $\beta-D$ Glucopyronosyl-1, 6, 7-trihydroxy-3-O-(4"-hydroxybenzoyl)9-One (II), ), 4-C- $\beta$-D Glucopyronosyl-1, 6, 8-trihydroxy-3, 7-O-(4"-hydroxybenzoyl)-9 and [4-C- $\beta$-DGlucopyronosyl-1, 3, 6, 8-tetrahydroxy7-O-(4"-hydroxybenzoyl)-9H-xanthen-9One I (Chaudhary and Khadabadi, 2012) ${ }^{[5]}$. The examination of the spines of the stem bark led to the isolation of a new freulic ester named trans-triacontyl-4-acetoxy-3-methoxy cinnamate and also some known ferulates and triterpenes. Apigenin, flavones, vivenin 2, saponarin, cosmetin, isovitexin, xanthomicrol were isolated from the methanolic extract of ceiba. It contains sugars such as arabinose, lactose, sucrose, glucose and fructose also various amino acids such as lysine, glycocol, etc were found. N-hexacosanol and palmitic acid were isolated from the plants. During the hydrolysis of methanolic gum it yielded 2.5-di-o-methyl-L-arabinose and 2,4-di-o-methyl-D-galactose (Karole et al., 2017) ${ }^{[13]}$. B. Ceiba fruit ethanolic extract and aqueous extract has tested for various classes of phytoconstituents. Alkaloids, anthraquinone, lycosides, tannins, proteins, hormones, saponins, flavanoids, sugars and various organic acids with mucilage (Gadge et al., 2009) ${ }^{[7]}$. Coumarins and Xanthones along with other organic compounds were discovered in a recent phytochemical screening of ceiba flowers. Two new compounds were discovered along with other known phytosconstituents. The structures of recognized compounds were defined on the basis of their spectral and by physical data comparing with literature as shamiminol. Compound referred to as compound 2 was elucidated as 3,4,5trimethoxyphenol-1-O[(2!1)xylopyranosyl-(6!1)-a-

rhamnopyranosyl]-b-glucopyranoside and named as simalin B. Simalin A was transuded as 6-O-(4-hydroxy-3-methoxy benzoyl)-a, a-trehalose and was named compound 1 (Joshi et al., 2014) ${ }^{[12] .}$

Various studies conducted on Bombax ceiba L plant resulted in the discovery of existing and new phytoconstituents. Compounds of ceiba may serve as a "guide" or "lead" in the discovery and formulation of these components into drugs. More and more study needs to be conducted for the revelation of such components in the future for better treatments in the future.

\subsection{Nutritional parameters}

The family of B.Ceiba is Bombacaceae commonly known as Semal in Uttarakhand. The leaves of B. Ceiba contain shamimin C-flavonol glycosides with major potency as a hypotensive agent. Young leaves, petioles and seed cake (with a little or no gossypol) are used as fodder for cattle. In addition to the flowers and fleshy calyx, the immature calyx known as Semargulla is eaten as a vegetable in Uttar Pradesh. The paste of its petals is mixed with breast milk and applied externally to heal the red eyes and from the root of B. Ceiba tonic is extracted for healing of waist pain (Saklani et al., 2013) ${ }^{[19]}$. Its certain parts are edible with nutritional values like Malvalese plants (Mostafa, 2018) ${ }^{[15]}$.

\subsection{Bombax ceiba bud and flower}

The chemical composition of calyx and flower of B. Ceiba was studied for ether extract of calyx and also the protein and phosphorous content that have been shown to be favourable compared with traditional vegetables such as turnips, pumpkin, carrots and cabbage, radishes (SpringerBriefs in Pharmacology and Toxicology, n.d.) ${ }^{[20]}$. The young and dried fruit of B. Ceiba is used in the measurement of disease and ulceration of the kidneys and bladder, chronic inflammation and includes type of dysuria and stranguria, although reasoning for its usage is not scientifically known (Gadge and Jalalpure, 2012) ${ }^{[6]}$. The physicochemical composition is given in the table below:

Table 1: Chemical composition of flower buds and calyces (Springer Briefs in Pharmacology and Toxicology, n.d.)

\begin{tabular}{|c|c|c|}
\hline Composition & Calyces & Flower \\
\hline Moisture $\%$ & 85.14 & 85.66 \\
\hline Protein $\%$ & 1.56 & 1.38 \\
\hline Carbohydrates\% $\%$ & 13.87 & 11.95 \\
\hline Ash\% & 1.00 & 1.09 \\
\hline Calcium $(\mathrm{mg} / 100 \mathrm{~g})$ & 95.00 & 92.25 \\
\hline Magnesium $(\mathrm{mg} / 100 \mathrm{~g})$ & 64.00 & 54.24 \\
\hline Phosphorous $(\mathrm{mg} / 100 \mathrm{~g})$ & 41.00 & 49.00 \\
\hline
\end{tabular}

\subsection{Stem bark}

The bark is thick and gluey, has a soft and soothing effect especially on the skin also used for wound healing the bark paste is ideal for skin rashes and causes nausea when consumed (Wahab et al., 2012) ${ }^{[23]}$. The stem bark in macroscopic study found to be pale-ash to silvery-gray on outside, brown on inside, $0.5-1 \mathrm{~cm}$ thick with rough outside with transverse and vertical cracks, and mucilaginous on chewing. Bark powder is red black in colour with, parenchyma cells, single bark of thick-walled, oval to irregular, stone cells, fragments of cork cell. Whereas, microscopic stem bark reveals a 10-15 layered structure containing irregular stone cells which are radially organized and elongated transversely into a thin-walled, cork cells covered with outer layers (SpringerBriefs in Pharmacology and Toxicology, n.d.) ${ }^{[20]}$.

\section{Study of bark of B.ceiba Linn is given below:}

Table 2: Study of stem bark of B. ceiba (Springer Briefs in Pharmacology and Toxicology, n.d.)

\begin{tabular}{|c|c|}
\hline Analysis & Value \\
\hline Foreign matter & $1 \%$ or less \\
\hline Constituents & Tannins, gums and saponins \\
\hline Alcohol-soluble extractive & $2 \%$ or less \\
\hline Water-soluble extractive & $7 \%$ or less \\
\hline Total ash & $13 \%$ or less \\
\hline Acid-insoluble ash & $2 \%$ or less \\
\hline
\end{tabular}

\subsection{Root}

The young roots of the plant has recorded useful in numerous ailments such as diarrhoea, diabetes, bladder borders ,urinary disorders, gynaecological problems, dysentery, heart disease, debility and impotence (Verma et al., 2011) ${ }^{[21]}$ Revealed by preliminary phyto chemical analysis of roots existence of 
tannins glycosides, saponins, cardiac flavonoids, hormones, phenols besides amino acids and carbohydrates. The phenolic content found in dried form of root powder was 4.85 percent and tannin is 1.70 percent (Saklani et al., 2013) ${ }^{[19]}$. Young root contain more sugars, carbohydrates such as starch and pectic substances as compared to the roots that are old, but they contain not much amount of oil, coloringmatter and cellulose (SpringerBriefs in Pharmacology and Toxicology, n.d.) ${ }^{[20]}$ The chemical analysis of bark less roots is given below;

Table 3: Chemical analysis of barkless root (Springer Briefs in Pharmacology and Toxicology, n.d.)

\begin{tabular}{|c|c|}
\hline Tests & Values (\%) \\
\hline Moisture & 7.5 \\
\hline Starch & 71.2 \\
\hline Sugars & 8.2 \\
\hline Proteins & 1.2 \\
\hline Fat & 0.9 \\
\hline Mineral matter & 2.1 \\
\hline Tannins & 0.15 \\
\hline Non tannins & 0.9 \\
\hline Cellulose & 2.0 \\
\hline Calcium & $93 \mathrm{mg} / 100 \mathrm{~g}$ \\
\hline
\end{tabular}

\subsection{Leaves}

Leaves are recorded to possess condensed tannins (Springer Briefs in Pharmacology and Toxicology, n.d.). Whole plant have medicinal relevance; for example, leaves of plant are stated to have been used for treatment of skin eruptions while flowers and root are known to have laxative, tonic, diuretic and restorative properties,. In addition, antioxidant and analgesic properties found in methanolic extract of leaves and mangiferin (xanthone obtained directly from the methanolic extract (Vieira et al., 2009) ${ }^{[22]}$. The studies on the phytoconstituents of the leaves however a flavanoid, isolated from plants viz mangiferin, was formerly wrongly interpreted as Shamimina new compound and correctly explained as Mangiferin (SpringerBriefs in Pharmacology and Toxicology, n.d.) ${ }^{[20]}$. Nutritional composition of leaves of B.ceiba $L$ is given below.

Table 4: Nutritional composition of B.ceiba $L$ leaves dry basis (Preparation of Value Added Products from Flower and Fruits of Bombax Ceiba (Simbal Tree), 2018)

\begin{tabular}{|c|c|}
\hline Nutrients & Values (\%) \\
\hline Carbohydrate & 1.48 \\
\hline Protein & 0.7 \\
\hline Fats & 0.75 \\
\hline Fibre & 2.85 \\
\hline Mineral & 13.23 \\
\hline Sodium & $19.07(\mathrm{mg} / 100 \mathrm{~g})$ \\
\hline $\mathrm{K}$ & $153.66(\mathrm{mg} / 100 \mathrm{~g})$ \\
\hline $\mathrm{Ca}$ & $177(\mathrm{mg} / 100 \mathrm{~g})$ \\
\hline
\end{tabular}

\subsection{Seed}

Bombax ceiba (Red silk cotton tree) belongs to family of Malvaceae, locally known as shimul harvest fruits that contain approximately $25-28$ per cent (w/w) of seed. Seeds, typically scrapped as agricultural-waste, contain a significant quantity of oil that ranges from $20-25$ percent and by weight cotton seed oil is equivalent to it. (Bora et al., 2018) ${ }^{[4]}$. In seed meal's chemical analysis showed moisture content $11.40 \%, 36.50 \%$ protein content, $0.80 \%$ fat content, $24.70 \%$ carbohydrate content, $19.90 \%$ crude fiber content, $24.72 \%$ mineral content and nutritional ratio of 1:0:7 (SpringerBriefs in Pharmacology and Toxicology, n.d.) ${ }^{[20]}$. It contains $1.21 \%$ myristic, $7.5 \%$ linoleic, $64.9 \%$ oleic, $23.6 \%$ palmitic, and $2.8 \%$ arachidic acids and in the industry like soap oil of Red silk-cotton is also a replacement for cotton seed oil. The oil is reported to consist of primarily sterulic acid and malvalic acid, some unsaturated fatty acids and a portion of cyclopropenoid fatty acids (Bora et al., 2018) ${ }^{[4]}$. The table below contains some physico-chemical properties of semal tree.

Table 5: Physico chemical properties of B.ceiba L seed (Bora et al., 2018) ${ }^{[4]}$.

\begin{tabular}{|c|c|}
\hline Property & Values \\
\hline Colour & Bright yellow \\
\hline Odour & Slightly unacceptable \\
\hline Free fatty acid & 8.42 \\
\hline Saponification value $(\mathrm{mg} \mathrm{KOH} / \mathrm{g})$ & 185.2 \\
\hline Iodine value $(\mathrm{g} \mathrm{I} / 100 \mathrm{~g})$ & 92.3 \\
\hline Specific gravity $\left(\mathrm{g} / \mathrm{cm}^{3}\right)$ & 0.91 \\
\hline Refractive Index $\left(30^{\circ} \mathrm{C}\right)$ & 1.469 \\
\hline Acid value of seed oil $(\mathrm{mg} \mathrm{KOH} / \mathrm{g})^{\mathrm{K})}$ & 16.25 \\
\hline Yield $\%$ & 28.3 \\
\hline
\end{tabular}

\subsection{Gum}

As a part of intrinsic metabolism in plants some formation of gum-resin can be noted on the other hand it is a sign of stress, ageing or due to treatment with certain chemicals and attack from pathogens.Gum exudes from Bombax ceiba to fight from infection or other practical disease. The exudates are therefore a result of pathogenesis. Gum is known as 'semulgum' and is used in medicinal purpose. (Babu and Shah, 1987) [3]. The mineral matter found in gum Viz purified is $8.9 \%$ and a small amount of catechol tannin. The various gallic and tannic acid sugars mixture can be seen in total hydrolysis of gum (SpringerBriefs in Pharmacology and Toxicology, n.d.) ${ }^{[20]}$. Physico chemical properties of the gum by two different extraction methods i.e. hot water extract and cold water extract with comparison to acacai gum shows that it possesses interesting properties and would make a great choice for pharmaceutical purpose (Audu-Peter et al., 2011) ${ }^{[2]}$ The table is given below.

Table 6: Physico-chemical properties of Gum (Audu-Peter et al., 2011) ${ }^{[2]}$

\begin{tabular}{|c|c|c|c|}
\hline Property & AC & HE & CE \\
\hline Moisture \% & 10.8 & 2.3 & 7.00 \\
\hline Fat content & 4.18 & 5.92 & 5.13 \\
\hline Swelling index & 2.8 & 7.9 & 7.6 \\
\hline $\mathrm{pH}$ of $2 \%$ solution at $23^{\circ} \mathrm{C}$ & 4.13 & 4.17 & 3.96 \\
\hline Hydration capacity (density of water is $0.997 \mathrm{gcm}^{-3}$ at $\left.23{ }^{\circ} \mathrm{C}\right)$ & 4.657 & 17.932 & 16.741 \\
\hline True density $\left(\mathrm{gcm}^{-3}\right)$ & 1.1705 & 2.2692 & 2.0392 \\
\hline
\end{tabular}




\section{Pharmacological importance 3.1 Anti-obesity}

Against high fat diet anti-obesity potential was generated obesity, likely due to FAS manipulation and in Wistar rats signalingPTP-1B because of existence of the active lupeol and flavanoids found in extract of Bombax ceiba Linn stem bark (Gupta et al., 2013) ${ }^{[10]}$.

\subsection{Antimicrobial activity}

Methanol extracts from Bombax ceiba have shown strong antibacterial activity (XU et al., 2017). Plant products were collected and homogenized washed, dissolved in organic solvents i.e. methanol and acetone. Performance was contrasted with the standard antimicrobials Piperacillin and Amikacin. Antibacterial activity performed by agar disk diffusion process against Klebsiella and pneumonia (Chaudhary \& Khadabadi, 2012) ${ }^{[5]}$.

\section{Hypotensive and hypoglycaemic activity}

Shamimin and lupeol [lup-20(29) en-3b-ol], which has a potent hypotensive function. It was extracted from bark of the ceiba head. BCBMM [filtrate of BCBM (Methanolic extract of defatted stem bark)] which is the most active part has recorded negative impact on the liver, kidneys and heart of mice with the dosage being $1000 \mathrm{mg} / \mathrm{kg} / \mathrm{d}$ (Rameshwar et al., 2014) ${ }^{[18]}$.

\subsection{Antiangiogenic activity}

Lupeol was tested for its Antiangiogenic activity and also checked for the cells for cytotoxicity against SK-MEL-2, A549. Also, the antiangiogenic activity was checked for cells of B16-F10. A strong inhibitory activity was displayed by lupeol with a inhibition rate of 80 percent and more at $50 \mu \mathrm{g} /$ mL.in vitro HUVEC tube. With all the three lines tested it was discovered that no major cytotoxicity was demonstrated by lupeol (ED50>30 $\mu \mathrm{g} / \mathrm{mL}$ ) (You et al., 2003) ${ }^{[25]}$.

\subsection{Hepatoprotective activity}

Chronic excessive alcohol intake may lead to serious injury to the liver. The extract from Flowers of Bombax ceiba (Family: Bombacaceae) has therapeutic impact of aqueous methanol were inspected against liver steatosis.. The study involved research time was eight weeks and seven groups were formed. The first party was used as control. The remaining six parties were classified into two types, three in each. The first group has been served a fat rich diet. The second group was given orally administered ethanol and fat diet. Standard fluvastatin drug in each category $(2 \mathrm{mg} / \mathrm{kg} / \mathrm{d})$ was handelled in one group. Oral treatment of BCE (200 mg / kg / d) was given to another group. No treatment was given to the third party. The $\mathrm{BCE}$ is responsible for great decrease in both body and liver weight. BCE extract enhances the effect on the liver activity of alcohol induced activity. The BCE extract substantially decreased (MDA) malondialdehyde level and increased the hepatic antioxidants. A great decrease was discovered in the serum lipid profiles: triglycerides (TG), low density lipoprotein (LDL) and total cholesterol (TC). Histopathological research shows caused fatty changes due to alcohol that has been changed by BCE treatment. The presence of phenolic compounds and flavanoids lead to an effective potential against alcohol- induced liver damage and also against anti-steatosis, inflammation and antioxidant activity in a data showed by BCE potential (Arafa et al., 2019) ${ }^{[1]}$.

\subsection{Cytotoxicity}

Benzo[a]pyrene (BaP) in HT1080 cells in methanolic flower extract of Bombax ceiba has been shown to have defensive effects on the cytotoxicity including two ascorbic acid derivatives and four butyrolactone were isolated and the estimate active ingredients were analyzed. Mangiferin, 16 extract compounds. BaP- induced cytotoxicity was reduced by some isolated compounds such as Quercetin, kaempferol, butyrolactone derivative and (-) loliolide (Nakashima et al., 2018) ${ }^{[16]}$.

\subsection{Analgesic effect}

Methanol extract from B. Ceiba leaves and their fractions and mangiferin have caused analgesic effect that is dose dependent on acetate and hot plate tests (Jain \& Verma, 2014) [11].

\subsection{Anti diabetic activity}

Antioxidant activity induced by isoorientin, vitexin, isomangiferin, quercetin, hexoside, mangiferinisovitexinand nigricanside may be the mechanism involved in the antidiabetic activity of the BCE.In a research study by (XU et al., 2017) ${ }^{[24]}$ the potential therapeutic effect of standard extract of B. Cdeibaleaves(BCE) was tested against rats induced with diabetic mellitus type 2 (T2DM) and its effects were recorded. $\mathrm{BCE}$ triggered in concentrations of fasting blood glucose major decrease and improved oral glucose tolerance in the T2DM rats. BCE displayed results that an excellent hypoglycaemic against rats with type two diabetes.

\subsection{Diuretic activity}

Diuretic activity was studied to employ a diuretic drug in which Urea is $1000 \mathrm{mg} / \mathrm{kg}$ p.o. and Frusemide is $25 \mathrm{mg} / \mathrm{kg}$, p.o. Oral administration of extracts total volume and report of urinary excretion of potassium, sodium and chloride is noted after 5 to 24 hours of oral administration. Ethanolic extract (200 and $400 \mathrm{mg} / \mathrm{kg}$, p.o.) showed a substantial improvement in total urinary volume and excretion of electrolytes in contrast to the control group (Gadge et al., 2009) ${ }^{[7]}$.

\subsection{Antioxidant activity}

In a research study by (Gandhare et al 2011) of B.ceiba bark. The DPPH activity of ethanolic extract was found to have an $\mathrm{IC}_{50}$ value of $94.66 \pm 0.049(\mu \mathrm{g} / \mathrm{ml})$. Whereas, the aqueous extract gave an $\mathrm{IC}_{50}$ value of $100.46 \pm 0.36$ against standard with an $\mathrm{IC}_{50}$ value of $91.53 \pm 0.31$.

\subsection{Other uses \\ Anabolic and Androgenic activity}

Young B. Ceiba root is traditionally used as an aphrodisiac in the Indian subcontinent. It is also known as Semal-musli. Its juice is considered to be, restorative, nutritious and sexually stimulating. In male albino rats freeze dried aqueous root extract has shown an anabolic effect when female rats are present. A increase in weight is observed and improvement in the frequency of mounting, and ejaculation was achieved (SpringerBriefs in Pharmacology and Toxicology, n.d.) ${ }^{[20]}$.

\section{Conclusion}

This review outlines the various uses of Bombax ceiba ranging from therapeutic to pharmacological activities. Herbal plants contain many therapeutic properties but cannot be used extensively as treatments. Therefore research is required to study their phytoconstituents so that they can serves as a 
guide for developing medicines in the coming time. Long history of B.Ceiba being used as medicine for various ailments; many traditional applications is validated by scientific research. Reviewing the scientific studies by different researchers in this paper gives a clear proof that the traditional claims on this plant are reliable and more research is required to discover more potential benefits of this plant. Apart from medicinal uses the plant is also used commercially for its wood, oil, gum and fodder, therefore it is hoped and required that more research is performed on this economical and ecological species to unlock its benefits.

\section{References}

1. Arafa AF, Foda DS, Mahmoud AH, Metwally NS, Farrag ARH. Bombax ceiba flowers extract ameliorates hepatosteatosis induced by ethanol and relatively moderate fat diet in rats. Toxicology Reports. 2019; 6:401-408. https://doi.org/10.1016/j.toxrep.2019.04.008

2. Audu-Peter JD, Vandi JK, Wuniah B. Evaluation of some physicochemical properties of Bombax gum. Journal of Pharmacy \& Bioresources. 2011; 6(2):78-83. https://doi.org/10.4314/jpb.v6i2.63333

3. Babu AM, Shah, JJ. Unusual Tissue Complexes Formed in Association with Traumatic Gum Cavities in the Stem of Bombax ceiba L. Annals of Botany. 1987; 59(3):293299. https://doi.org/10.1093/oxfordjournals.aob.a087318

4. Bora MM, Deka C, Ahmed Tapadar S, Jha DK, Kakati, DK. Alkyds from red silk-cotton (Bombax ceiba) seed oil and investigation on their microbial degradation. Progress in Organic Coatings. 2018; 124:71-79. https://doi.org/10.1016/j.porgcoat.2018.08.008

5. Chaudhary $\mathrm{P}$, Khadabadi S. Bombax ceiba Linn: Pharmacognosy, Ethnobotany and Phyto-pharmacology. Pharmacognosy Communications. 2012; 2(3):02-09. https://doi.org/10.5530/pc.2012.3.2

6. Gadge NB, Jalalpure SS. Curative treatment with extracts of Bombax ceiba fruit reduces risk of calcium oxalate urolithiasis in rats. Pharmaceutical Biology. 2012; 50(3):310-317.

https://doi.org/10.3109/13880209.2011.604332

7. Gadge NB, Jalalpure SS, Pawase KB. Preliminary phytochemical screening and diuretic activity of Bombax ceiba L. fruit extracts. Pharmacologyonline. 2009; 3:188194.

8. Gandhare B, Soni N, Dhongade HJ. In vitro antioxidant activity of Bombax ceiba. Int. J Biomed. Res. 2010; $1(2): 31-36$

9. Griffiths AD, Philips A, Godjuwa C. Harvest of Bombax ceiba for the Aboriginal arts industry, central Arnhem Land, Australia. Biological Conservation. 2003; 113(2):295-305. https://doi.org/10.1016/S00063207(02)00419-6

10. Gupta P, Goyal R, Chauhan Y, Sharma PL. Possible modulation of FAS and PTP-1B signaling in ameliorative potential of Bombax ceiba against high fat diet induced obesity. BMC Complementary and Alternative Medicine. 2013; 13:1-9. https://doi.org/10.1186/1472-6882-13-281

11. Jain V, Verma SK. Assessment of credibility of some folk medicinal claims on bombax ceiba L. Indian Journal of Traditional Knowledge. 2014; 13(1):87-94.

12. Joshi KR, Devkota HP, Yahara S. Simalin A and B: Two new aromatic compounds from the stem bark of Bombax ceiba. Phytochemistry Letters. 2014; 7(1):26-29. https://doi.org/10.1016/j.phytol.2013.09.005
13. Karole S, Gautam G, Gupta S. Pharmacognostic and Pharmacological. 2017; 6(3).

14. Mehta P, Bothiraja C, Mahadik K, Kadam S, Pawar A. Phytoconstituent based dry powder inhalers as biomedicine for the management of pulmonary diseases. Biomedicine and Pharmacotherapy. 2018; 108:828-837. https://doi.org/10.1016/j.biopha.2018.09.094

15. Mostafa NM. $\beta$-amyrin rich Bombax ceiba leaf extract with potential neuroprotective activity against scopolamine-induced memory impairment in Rats. Records of Natural Products. 2018; 12(5):480-492. https://doi.org/10.25135/rnp.47.17.10.062

16. Nakashima S, Oda Y, Ogawa Y, Nakamura S, Uno M, Kishimoto M. et al. Protective effects of compounds in bombax ceiba flower on benzo[a]pyrene-induced cytotoxicity. Natural Product Communications. 2018; 13(5):561-564. https://doi.org/10.1177/1934578x1801300512

17. Preparation of value added products from flower and fruits of Bombax Ceiba ( Simbal tree), May, 2018.

18. Rameshwar V, Kishor D, Siddharth G, Sudarshan G. A Pharmacognostic and pharmacological overview on Bombax ceiba. Scholars Academic Journal of Pharmacy Online) Sch. Acad. J Pharm. 2014; 3(2):2320-4206. www.saspublisher.com

19. Saklani S, Chandra S, Mishra AP. Nutritional profile, antinutritional profile and phytochemical screening of Garhwal Himalaya medicinal plant Dioscorea Alata tuber. International Journal of Pharmaceutical Sciences Review and Research. 2013; 23(2):42-46.

20. SpringerBriefs in Pharmacology and Toxicology. (n.d.).

21. Verma SK, Jain V, Katewa SS. Anabolic effect of Bombax Ceiba Linn. root in idiopathic involuntary weight loss - a case study. Journal of Herbal Medicine and Toxicology. 2011; 5(1):1-5.

22. Vieira TO, Said A, Aboutabl E, Azzam M, CreczynskiPasa TB. Antioxidant activity of methanolic extract of Bombax ceiba. Redox Report. 2009; 14(1):41-46. https://doi.org/10.1179/135100009X392485

23. Wahab S, Hussain A, Ahmad P, Usmani S. Ethanobotanical, pharmacognostical and physicochemical studies of stem bark of Bombax ceiba L., commonly growing in eastern Uttar Pradesh region of India. Pharmacognosy Journal. 2012; 4(32):55-60. https://doi.org/10.5530/pj.2012.32.10

24. XU GK, QINX Y, WANG GK, XIE GY, LI X Sen, SUN $\mathrm{CY}$ et al. Antihyperglycemic, antihyperlipidemic and antioxidant effects of standard ethanol extract of Bombax ceiba leaves in high-fat-diet- and streptozotocin-induced Type 2 diabetic rats. Chinese Journal of Natural Medicines. 2017; 15(3):168-177. https://doi.org/10.1016/S1875-5364(17)30033-X

25. You YJ, Nam NH, Kim Y, Bae KH, Ahn BZ. Antiangiogenic activity of lupeol from Bombax ceiba. Phytotherapy Research. 2003; 17(4):341-344. https://doi.org/10.1002/ptr.1140 